\title{
Changes in corneal thickness and corneal endothelial cell density after phacoemulsification cataract surgery: a double-blind randomized trial
}

\author{
Shahram Bamdad ${ }^{1}$, Alireza Bolkheir ${ }^{2}$, Mohammad Reza Sedaghat ${ }^{3}$, Mahsa Motamed ${ }^{4}$
}

${ }^{1}$ M.D., Associate Professor of Ophthalmology, Poostchi Ophthalmology Research Center, Shiraz University of Medical Sciences, Shiraz, Iran

${ }^{2}$ M.D., Resident of Ophthalmology, Poostchi Ophthalmology Research Center, Shiraz University of Medical Sciences, Shiraz, Iran

${ }^{3}$ M.D., Professor of Ophthalmology, Department of Ophthalmology, Faculty of Medicine, Mashhad University of Medical Sciences, Mashhad, Iran

${ }^{4}$ M.D., Poostchi Ophthalmology Research Center, Shiraz University of Medical Sciences, Shiraz, Iran

\section{Type of article: Original}

\begin{abstract}
Background: Age-related cataract is a leading cause of visual impairment, considered a global health burden, it is responsible for over $47 \%$ of blindness worldwide. Surgical intervention is usually the treatment of choice and phacoemulsification cataract surgery with implantation of an intraocular lens is the most common procedure, which may have several complications.

Objectives: To determine the effects of phacoemulsification surgery on corneal endothelial cell density and corneal thickness in patients undergoing cataract surgery.

Methods: The present study was conducted on patients diagnosed with immature senile cataract requiring surgical intervention from November 2013 to 2014 in Khatam al Anbia Hospital (a tertiary ophthalmology center). Physical examination included best-corrected visual acuity using the Snellen chart, refraction, slit-lamp bio-microscopy for anterior chamber evaluation, keratometry, Goldman tonometry, gonioscopy, and dilated indirect ophthalmoscopy, pachymetry, specular microscopy and biometry. Surgery was performed by similar method and technique in all patients. The change in the corneal endothelial cell count or density and central corneal thickness (CCT) number were compared preoperatively and one day, one week, one month, and three months post-operatively.

Results: A total of 92 eyes of 85 patients (43 females and 42 males with mean age of $62.1 \pm 12.2$ years) were studied. Patients' visual acuity improved (log MAR: $1 \pm 0.5$ preoperatively to $0.45 \pm 0.34$ post-operatively) $(\mathrm{p}=0.001)$. There was $11.4 \%$ endothelial cell loss (ECL) and significant decrease in ECC (from 2,791.15 \pm 99.86 to $2,472.87 \pm 472.14)(\mathrm{p}=0.04)$. The central corneal thickness increased significantly (from $530.47 \pm 2.60$ to $540.91 \pm 36.07)$. Diabetic patients $(12.9 \%)$ had a statistically significant higher ECL rate after phacoemulsification ( $14.6 \%$ versus $8.7 \%$ respectively, $\mathrm{p}=0.002$ ).

Conclusion: Phacoemulsification resulted in significant corneal endothelial damage, which is particularly important in patients with a borderline reservoir of endothelial cell, such as diabetic patients, which highlights the necessity of refining the current surgical methods and instruments to minimize the endothelial damage.

Trial registration: The trial was registered in the Thai clinical trial registry (http://www.clinicaltrials.in.th) with the ID: TCTR20171122001.

Funding: The study was supported by a research grant of Mashhad University of Medical Sciences.

Keywords: Cataract, Phacoemulsification, Corneal endothelial cell density, Corneal thickness
\end{abstract}

\section{Corresponding author:}

Associate Professor Dr. Shahram Bamdad, Department of Ophthalmology, Khalili Hospital, Shiraz University of Medical Sciences, Postal code: 713453484, Shiraz, Iran.

Tel: +98.7136291779, Fax: +98.7136279373, Email: shahrambamdad@yahoo.com

Received: November 29, 2016, Accepted: November 27, 2017, Published: April 2018

iThenticate screening: December 20, 2017, English editing: March 20, 2018, Quality control: April 12, 2018

(C) 2018 The Authors. This is an open access article under the terms of the Creative Commons Attribution-NonCommercialNoDerivs License, which permits use and distribution in any medium, provided the original work is properly cited, the use is non-commercial and no modifications or adaptations are made. 


\section{Introduction}

Visual impairment (VI) is a global health burden associated with increased morbidity in different ethnic groups (1 3 ). Around the world, there are more than 190 million people suffering from visual impairment, 32 million of whom are blind (4). Worldwide, age-related cataract is a leading cause of visual impairment, characterized by the hardening and clouding of the normally transparent crystalline lens, resulting in partial to complete visual loss $(5,6)$. The condition is responsible for over $47 \%$ of blindness worldwide (7). As well as the direct consequence of blindness and visual impairment, the risk of bodily harm such as hip injury, increases for people with cataracts (8). There is a greater restriction to continued independent living leading to a reduction in the general quality of life in individuals with non-operated cataracts (9). Although mild cataracts can be treated with a change in the prescribed glasses, age-related cataract progression has an unpredictable rate (10). Moreover, lenticular changes associated with cataracts can be the cause of index myopia, and rapidly increasing refractive errors can lead to significant anisometropia. In these circumstances, refractive correction can be problematic and in the long term, best managed by surgical intervention (11). The most common cataract procedure is phacoemulsification cataract surgery with the implantation of a posterior chamber (behind the iris), intraocular lens (IOL) within the capsular bag (12), although there are other innovative procedures with higher costs and surgical duration, like femtosecond laser-assisted cataract surgery, which are not available in all centers (13). Although phacoemulsification has fewer complications compared to previous types of cataract operations, it still carries important undesirable side effects, such as intraoperative complications [Vitreous loss (1.5\%), Posterior capsular rupture (2.8\%)] and post-operative complications [Posterior capsule opacification (5.8\%), Retinal detachment (0.08\%), Cystoid macular oedema (1\%)] (14). As another complication, phacoemulsification can lead to significant loss of endothelial cells, corneal thickness and corneal endothelial cell density during cataract surgery, resulting in prolonged corneal edema (15-17). In severe cases, corneal decompensation may often occur associated with decreased vision necessitating subsequent corneal transplantation (18). Considering the wide prevalence of cataract and cataract-related blindness in developing countries and, specifically, in Iran (19), and with a rapidly aging population, this problem is predicted to multiply in future. The ethnic differences in ocular parameters have suggested that the surgical outcome of cataract surgery may be different in different ethnicities/races $(20,21)$, while to the best of our knowledge, there are few studies in our country investigating the post-operative complications of cataract surgery (22). Considering the increased cataract surgical rate in our country from about 2.5 times from 526 to 1,331 per million over five years (2000-2005) (23), it is necessary to determine the surgical outcome of cataract surgery in Iranian patients. Therefore, this study aimed to determine the post-operative complications of phacoemulsification in patients undergoing cataract surgery.

\section{Material and Methods}

\subsection{Study design}

The present study was designed as a clinical trial to determine the effects of phacoemulsification surgery on corneal endothelial cell density and corneal thickness in cataract patients. The study was prospectively conducted during a 12 month period from November 2013 to November 2014 in Khatam al Anbia Hospital (a tertiary ophthalmology centre), affiliated to the Mashhad University of Medical Sciences, Mashhad, Iran.

\subsection{Participants}

Patients who referred to Khatam al Anbia Hospital from November 2013 to November 2014 were selected as the study population. For assessment of patients' recruitment based on the inclusion and exclusion criteria, first, a detailed medical history was obtained and a thorough physical examination was done by a surgeon in an outpatient department to recruit subjects properly for the study. The examinations included a complete preoperative, bestcorrected visual acuity using the Snellen chart, refraction, slit-lamp bio-microscopy for anterior chamber evaluation, keratometry, Goldman tonometry, gonioscopy, and dilated indirect ophthalmoscopy for evaluation of fundus and the posterior segment, pachymetry (SonoMed 4000, Japan), specular microscopy (Tomey, EM-1000, Japan) and biometry (Optic, Mizar, Germany). Figure 1 shows the CONSORT diagram of the study.

\subsection{Selection criteria}

All the patients diagnosed with senile cataract having visual impairment requiring surgical intervention and willing to participate during the study period were potentially eligible for inclusion. Subjects with the following conditions were excluded: traumatic cataract, mature and hypermature cataract, nuclear sclerosing grade 4 cataract, pseudoexfoliation syndrome, conjunctival scarring, significant corneal opacity, glaucoma, ocular hypertension, uveitis, vitreoretinal pathology, previous intra-ocular surgery, intraoperative complications during cataract surgery, collagen vascular disease, any active ocular disease, high myopia, high hyperopia (axial length less than $15 \mathrm{~mm}$ ) age younger than 40 years, preoperative endothelial cell count less than 1,000 cells per square millimetre, or 
preoperative anterior chamber depth less than $2.5 \mathrm{~mm}$, dry-eye syndrome, iris neovascularization, or other abnormalities that could cause significant endothelial cell impairment independent of surgery.
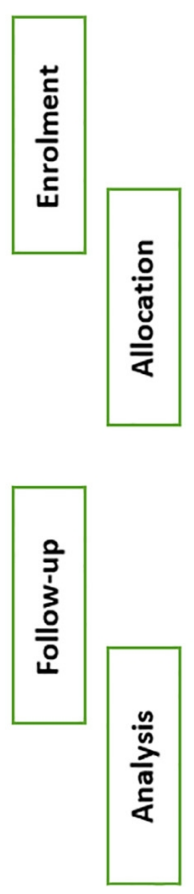

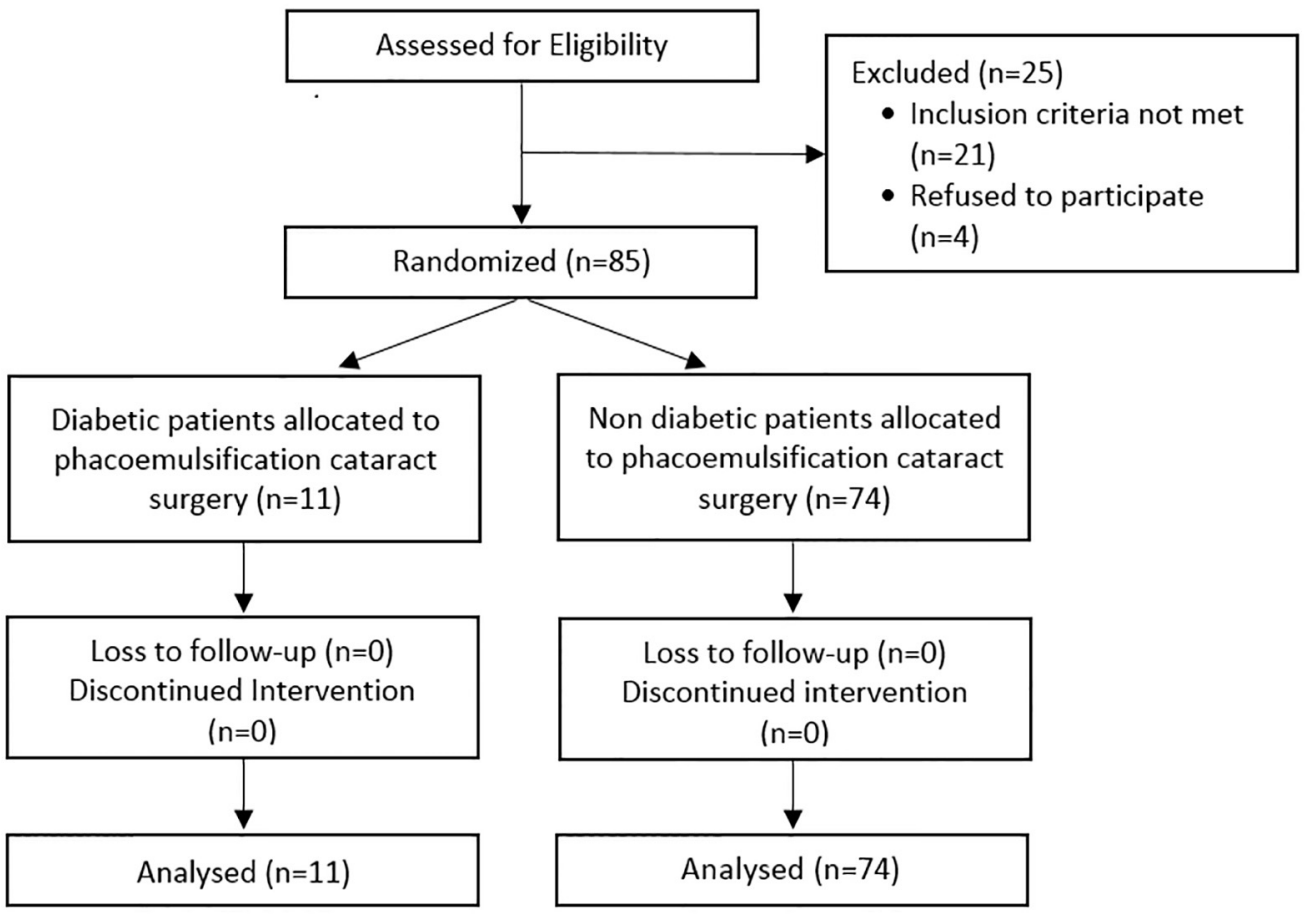

Figure 1. CONSORAT diagram of the study

\subsection{Interventions}

A senior and experienced surgeon performed surgery for all patients at Khatam al Anbia Hospital in order to minimize bias. Preoperatively, the pupil was dilated with a cocktail of scopolamine $0.3 \%$, tropicamide $1 \%$, and phenylephrine $10 \%$. All patients underwent local anaesthesia, administered by a standard retrobulbar injection of 4 $\mathrm{mL}$ lidocaine $2 \%$ or a technique in which a sponge is soaked with oxybuprocaine $2 \%$, applied to the conjunctiva near the limbus, and left in place for 10 minutes before surgery. An oculopressure balloon was used on every patient to apply approximately $30 \mathrm{mmHg}$ to the eye for about 10 minutes before surgery. All patients had a small incision of phacoemulsification with topical anaesthesia. The two-plane clear corneal main incision was created at 12 o'clock using a $2.75 \mathrm{~mm}$ metal keratome (slit knife 2.75 angled, Alcon Laboratories, Inc.). The single-plane side-port incisions were created at 9 o'clock and 3 o'clock with a $1.2 \mathrm{~mm}$ metal keratome (side-port knife, dual bevel, angled, Alcon Laboratories, Inc.). After the instillation of the ophthalmic viscosurgical device (OVD), sodium hyaluronate $1.0 \%$ (Healon) was injected into the anterior chamber to protect the endothelium, a continuous curvilinear capsulorhexis was created using a self-bent 27-gauge needle through a side-port incision. The intended diameter was $5.0 \mathrm{~mm}$. The standard microflow needle with an inner tip diameter of $0.91 \mathrm{~mm}$, decreasing to $0.51 \mathrm{~mm}$, and an angulation of 30 degrees at the opening was used. Micro-coaxial phacoemulsification was performed with Storz Millennium phacoemulsification machine (Bausch \& Lomb, Inc.). During the surgical procedures, the Phaco machine settings were identical for all patients with the same cataract density. The infusion bottle was set $1 \mathrm{~m}$ high (at room temperature). The aspiration flow rate and the set vacuum level were $35 \mathrm{~mL} / \mathrm{min}$, and $400 \mathrm{or} 600 \mathrm{~mm} \mathrm{Hg}$, respectively. We used a stop-and-chop technique for phacoemulsification. Through the nasal and temporal incisions, bimanual irrigation/aspiration (I/A) were performed for removal of the remaining cortex, followed by the polishing of the posterior capsule. A three-piece, 6-mm folding silicone/Prolene (Ethicon, Inc., Somerville, NJ) lens was then inserted into the capsular bag.

\subsection{Outcomes}

Two outcome measures were considered for the description and analysis of the change in the endothelial cell characteristics after surgery. The primary measured outcome was a change in corneal endothelial cell count or 
density (cells per square millimetre of the corneal surface). The central corneal thickness (CCT) measured in $\mathrm{mm}$ was the secondary outcome of measure.

\subsubsection{Central Corneal Thickness (CCT)}

The CCT was measured using pachymetry (SonoMed 4000, Japan), preoperatively and one day, one week, one month, and three months post-operatively. The pachymeter was pre-calibrated for all measurements. The CCT was measured with the patient seated upright. A hand-held probe was aligned on the central cornea as perpendicularly as possible. Ten readings were obtained and averaged. The same observer took all measurements.

\subsubsection{Endothelial Cell Counts (ECC)}

The ECC was measured using a non-contact specular microscope (Tomey, EM-1000, Japan) pre- and postoperatively (4 times as CCT). The central method was used for cell counting. Approximately 50 to 60 cells were counted manually from each photograph in the semiautomatic cell-density algorithm of the microscope. Three central fields were counted, and the average of these counts was used to represent endothelial cell density (ECD) at any point of time. Endothelial cell loss was evaluated as follows: Endothelial cell loss = (preoperative cell countpostoperative cell count/preoperative cell count) $\times 100$. One examiner was masked as to which group the images belonged. At each visit, three photographs were taken of each eye.

\subsection{Sample size}

A total of 92 eyes of 85 patients ( 43 females and 42 males with mean age of $62.1 \pm 12.2$ years) were studied. The following formula was used in determining the minimum required sample size with a power of $80 \%$ and a $5 \%$ level of significance, in which s stands for the variance of the target variable, $d$ is the maximum acceptable error and $a$ is the probability of error falling outside $\mathrm{d}\left(\mathrm{n}=\mathrm{s}^{2} \mathrm{a}^{2} / \mathrm{d}^{2}\right)$.

\subsection{Statistical methods}

Data were analyzed by SPSS version 18 (SPSS Inc., Chicago, IL, USA). Data were presented as mean \pm standard deviation (SD). Normal distribution of data was checked by Kolmogorov-Smirnov test. The $95 \%$ confidence intervals for the means of data were calculated, and the significance of differences between independent variable was assessed using independent-samples t-tests. Normally distributed continuous variables were compared using ttest. A Wilcoxon signed rank test was used in case of a non-parametric analysis. A two-sided p-value $<0.05$ was considered statistically significant.

\subsection{Research ethics}

All patients gave their written informed consent after being informed about the study design and objectives. The study protocol was approved by the Ethics Committee of Mashhad University of Medical Sciences (Ref. no.: 13543). Participation in the study was voluntarily and participants could leave the study whenever they wished to, without any alterations in their treatment process.

\section{Results}

A total of 92 eyes of 85 patients, 43 females and 42 male, with mean age of $62.1 \pm 12.2$ were studied. Baseline preoperative characteristics of the studied patients are summarized in Table 1. There was a statistically significant improvement in patients' visual acuity, measured in $\log$ MAR. Preoperatively, mean log MAR (log of the Minimum Angle of Resolution) was $1 \pm 0.5$, increasing to $0.45 \pm 0.34$ post-operatively ( $\mathrm{p}=0.001)$. A non-parametric Wilcoxon Singed Rank Test with a p-value of 0.04, revealed a significant decrease in ECC from 2,791.15 \pm 99.86 to $2,472.87 \pm 472.14$ accounting for an endothelial cell loss (ECL) value of $11.4 \%$. Both the paired-samples t-test and the Wilcoxon singed Rank test showed a significant increase in central corneal thickness from $530.47 \pm 2.60$ to a value of $540.91 \pm 36.07$. Overall, eleven patients were diabetic, accounting for $12.9 \%$ of the total. Diabetic patients had a statistically significant higher rate of endothelial cell loss after phacoemulsification $(14.6 \%$ versus $8.7 \%$ respectively, $\mathrm{p}=0.002$ ). Table 2 reflects the changes in primary and secondary outcomes of measure following phacoemulsification. 
Table 1. Baseline pre-operative characteristics of patients

\begin{tabular}{|l|l|l|}
\hline \multicolumn{2}{|l|}{ Variables } & Mean \pm SD / n (\%) \\
\hline Age (years) & No & $62.1 \pm 12.2$ \\
\hline Diabetes mellitus & Yes & $74(87)$ \\
\hline \multirow{2}{*}{ Gender } & Female & $11(12.9)$ \\
\cline { 2 - 3 } & Male & $43(50.6)$ \\
\hline \multirow{2}{*}{ IntraOP VL } & Yes & $42(49.4)$ \\
\cline { 2 - 3 } & No & $2(4.3)$ \\
\cline { 2 - 3 } & Unknown & $41(89.1)$ \\
\hline Nuclear Sclerosis & $3(6.5)$ \\
\hline Pre-OP VA (LogMAR) & $2.0 \pm 1.0$ \\
\hline Pre-OP MeanKR (D) & $0.78 \pm 1.59$ \\
\hline Pre-OP AXL (mm) & $43.13 \pm 8.26$ \\
\hline Pre-OP ACD (mm) & $22.46 \pm 5.34$ \\
\hline PSCC & $2.00 \pm 3.33$ \\
\hline IOP (mmHg) & $2.4 \pm 0.8$ \\
\hline Pre-OP Average Cell Area (smcm) & $13.5 \pm 3.6$ \\
\hline Pre-OP ECC & $396.56 \pm 127.13$ \\
\hline Pre-OP CV & $2791.15 \pm 1002.14$ \\
\hline Pre-OP CCT (mcm) & $91.78 \pm 79.01$ \\
\hline
\end{tabular}

Intraop $\mathrm{VL}=$ intraoperative vitreous loss, $\mathrm{VA}=$ visual acuity, Mean $\mathrm{KR}=$ mean keratometry, $\mathrm{AXL}=$ axial length, $\mathrm{ACD}=$ anterior chamber depth, $\mathrm{PSCC}=$ posterior subcapsular cataract, $\mathrm{IOP}=$ intra ocular pressure, $\mathrm{ECC}=$ endothelial cell count, $\mathrm{CV}=$ corneal volume, $\mathrm{CCT}=$ central corneal thickness

Table 2. Postoperative changes of Endothelial Cell Count, Average Cell Area ( $\mu \mathrm{m} 2)$, and Central Corneal Thickness

\begin{tabular}{|l|l|l|l|l|}
\hline Variables & Pre-op $(\mathrm{M} \pm \mathrm{SD})$ & Postop $(\mathrm{M} \pm \mathrm{SD})$ & Preop-Postop/Preop & p-value \\
\hline Endothelial Cell Count & $2791.15 \pm 99.86$ & $2472.87 \pm 472.14$ & ECL $(11.4 \%)$ & $0.04^{1}$ \\
\hline Average Cell Area $\left(\mu \mathrm{m}^{2}\right)$ & $396.55 \pm 155.82$ & $418.21 \pm 67.49$ & $21.66(5.4 \%)$ & $0.02^{2}$ \\
\cline { 5 - 6 } & & & & $0.013^{1}$ \\
\hline $\mathrm{CCT}^{*}(\mathrm{mcm})$ & $530.47 \pm 2.60$ & $540.91 \pm 36.07$ & $1.8 \%$ & $0.00^{2}$ \\
\hline LogMAR & & & & $0.02^{1}$ \\
\hline
\end{tabular}

$\mathrm{CCT}=$ central corneal thickness; 1 : Wilcoxon singed rank test; 2 : $\mathrm{t}$-test

\section{Discussion}

To the best of our knowledge, the present study is the second study to evaluate the effects of phacoemulsification on corneal endothelial cell count in an Iranian population. We identified several Western studies with comparable findings. We reported a value of $11.4 \%$ for mean endothelial cell loss after phacoemulsification, which is in the reported range of $4-17.5 \%$ in the literature $(16,17,24-28)$. The wide range of reported endothelial cell loss in different studies can be explained through various surgical techniques, different patient populations, and time points of ECC evaluation after surgery. Several intraoperative variables including the incision type, used OVD, type of IOL, composition of the irrigation solution, total phaco energy, and location of the active phacoemulsification have been proposed as a determinant of endothelial damage (29-31). However, our reported ECL is relatively higher compared to most of the existing literature. This could be attributed to higher surgery time, lower quality of viscoelastic material and less accurate measurements. In addition, diabetic patients had higher rates of ECL in our study. Overall, it is well known that the ultrasound application during phacoemulsification can lead to endothelial cell damage in cataract surgery due to mechanical trauma from sonic waves and from thermal injury (32). Central corneal thickness (CCT) was the secondary outcome of measure in this study. We found a mean CCT of $530.47 \pm 2.60 \mathrm{~mm}$ preoperatively, which increased to $540.91 \pm 36.07$ on post-operation Day 1 . The reflected $1.8 \%$ increase in CCT could be explained by corneal edema occurring as a result of damage to corneal endothelium, which is specifically observed in patients having higher ECL. This is compatible with the findings of Lundberg et al., who indicated a clinically significant postoperative corneal edema to be strongly associated with a clinically significant corneal endothelial cell loss (33). Other investigators have reported a $2-10 \%$ increase in CCT in the immediate postop investigations, depending on the viscoelastic regimens (34). In addition, postoperative corneal edema is 
influenced by many factors (35) including previous corneal pathology, the patient's age (36), and a postoperative rise in intraocular pressure (37). It is proposed that modifications of phacoemulsification techniques be considered in order to decrease postoperative corneal swelling, facilitating visual rehabilitation following surgery.

Another aspect of our findings yet to be discussed is about the contribution of diabetes mellitus to the degree of endothelial cell loss following cataract surgery. In our study, diabetic patients had a statistically significant higher rate of endothelial cell loss after phacoemulsification (14.6\% versus $8.7 \%$ ). A number of studies have also reported similar findings in which diabetes mellitus has been proposed as a possible risk factor for increased endothelial damage after cataract surgery (38-40). Mathew et al. reported a 9.3\% ECL in diabetics compared to a value of 7.7\% in normal controls (39). In another study conducted by Hugod, diabetic subjects were found to have a $6.4 \%$ ECL compared to $1.4 \%$ for non-diabetic subjects (38). This might be explained through greater metabolic stress imposed on diabetic endothelium leading to less functional reserve compared to euglycemic cataract patients. The study subjects had a statistically significant higher postoperative average corneal cell area compared to a preoperative state $(418.21 \pm 67.49 \mu \mathrm{m} 2$ versus $396.55 \pm 155.82 \mu \mathrm{m} 2)$. The increase in corneal cell area could be perceived as possible compensatory mechanism in response to corneal endothelial cell loss. Overall, it is widely accepted that ECL occurs as an inevitable consequence of cataract surgery. However, precise patient and surgical technique selection could potentially improve the outcome of this widely practised surgical intervention (41). This study adds further evidence to the role of diabetes mellitus as a risk factor responsible for increased ECL following phacoemulsification.

\section{Conclusions}

Phacoemulsification with the current method could result in significant corneal endothelial damage. This is particularly important in patients with a borderline reservoir of endothelial cell, such as diabetic patients, which highlights the necessity to refine the current surgical methods and instruments to minimize the endothelial damage. The possible limitations of this study were the relatively small number of studied subjects, heterogeneous nature of the population regarding other coexisting medical conditions and unsuccessful follow-ups of the subjects. Nonetheless, our findings add further evidence to the literature regarding the role of diabetes mellitus as a risk factor responsible for increased ECL following phacoemulsification. The results of this study suggests that future randomized studies could determine the surgical outcome of phacoemulsification in a larger sample between patients with and without diabetes.

\section{Acknowledgments:}

This paper was extracted from an ophthalmology residency thesis at Mashhad University of Medical Sciences in Mashhad, Iran. The authors appreciate the assistance and cooperation provided by the staff of the Ophthalmology Department of Khatam al Anbia Hospital and sincerely appreciate all of the patients who participated in this study.

\section{Trial registration:}

The trial was registered in the Thai clinical trial registry (http://www.clinicaltrials.in.th) with the ID: TCTR20171122001.

\section{Funding:}

The study was supported by a research grant of Mashhad University of Medical Sciences.

\section{Conflict of Interest:}

There is no conflict of interest to be declared.

Authors' contributions:

All authors contributed to this project and article equally. All authors read and approved the final manuscript.

\section{References:}

1) Clemons TE, Kurinij N, Sperduto RD. Associations of mortality with ocular disorders and an intervention of high-dose antioxidants and zinc in the Age-Related Eye Disease Study: AREDS Report No. 13. Arch Ophthalmol. 2004; 122(5): 716-26. doi: 10.1001/archopht.122.5.716. PMID: 15136320, PMCID: PMC1473208.

2) Foong AW, Fong CW, Wong TY, Saw SM, Heng D, Foster PJ. Visual acuity and mortality in a chinese population. The Tanjong Pagar Study. Ophthalmology. 2008; 115(5): 802-7. doi: 10.1016/j.ophtha.2007.04.066. 
3) Knudtson MD, Klein BE, Klein R. Age-related eye disease, visual impairment, and survival: the Beaver Dam Eye Study. Archives of ophthalmology. 2006; 124(2): 243-9. doi: 10.1001/archopht.124.2.243.

4) Jonas JB, Bourne RR, White RA, Flaxman SR, Keeffe J, Leasher J, et al. Visual impairment and blindness due to macular diseases globally: a systematic review and meta-analysis. American journal of ophthalmology. 2014; 158(4): 808-15. doi: 10.1016/j.ajo.2014.06.012.

5) Duerksen R, Limburg H, Carron JE, Foster A. Cataract blindness in Paraguay--results of a national survey. Ophthalmic epidemiology. 2003; 10(5): 349-57. doi: 10.1076/opep.10.5.349.17326.

6) Zheng Y, Lavanya R, Wu R, Wong WL, Wang JJ, Mitchell P, et al. Prevalence and causes of visual impairment and blindness in an urban Indian population: the Singapore Indian Eye Study. Ophthalmology. 2011; 118(9): 1798-804. doi: 10.1016/j.ophtha.2011.02.014.

7) Resnikoff S, Pascolini D, Etya'ale D, Kocur I, Pararajasegaram R, Pokharel GP, et al. Global data on visual impairment in the year 2002. Bull World Health Organ. 2004; 82(11): 844-51. doi: /S004296862004001100009. PMID: 15640920, PMCID: PMC2623053.

8) Ivers RQ, Cumming RG, Mitchell P, Simpson JM, Peduto AJ. Visual risk factors for hip fracture in older people. Journal of the American Geriatrics Society. 2003; 51(3): 356-63. doi: 10.1046/j.15325415.2003.51109.x.

9) Taylor HR, Pezzullo ML, Keeffe JE. The economic impact and cost of visual impairment in Australia. Br J Ophthalmol. 2006; 90(3): 272-5. doi: 10.1136/bjo.2005.080986. PMID: 16488942, PMCID: PMC1856946.

10) Allen D. Cataract. BMJ Clin Evid. 2011; 2011. PMID: 21718561 , PMCID: PMC3275311.

11) Dandona R, Dandona L. Refractive error blindness. Bulletin of the World Health Organization. 2001; 79(3): 237-43. PMID: 11285669, PMCID: PMC2566380.

12) Trivedi R, Werner L, Apple D, Pandey S, Izak A. Post cataract-intraocular lens (IOL) surgery opacification. Eye. 2002; 16(3): 217-41. doi: 10.1038/sj.eye.6700066.

13) Trinh L, Denoyer A, Auclin F, Baudouin C. Femtosecond laser-assisted cataract surgery. J Fr Ophtalmol. 2015; 38(7): 646-55. doi: 10.1016/j.jfo.2015.05.002. PMID: 26206508.

14) de Silva SR, Riaz Y, Evans JR. Phacoemulsification with posterior chamber intraocular lens versus extracapsular cataract extraction (ECCE) with posterior chamber intraocular lens for age-related cataract. Cochrane Database Syst Rev. 2014; 1: Cd008812. doi: 10.1002/14651858.CD008812.pub2. PMID: 24474622.

15) Bourne WM, Waller RR, Liesegang TJ, Brubaker RF. Corneal trauma in intracapsular and extracapsular cataract extraction with lens implantation. Archives of ophthalmology. 1981; 99(8): 1375-6. doi: 10.1001/archopht.1981.03930020249006.

16) Thakur SK, Dan A, Singh M, Banerjee A, Ghosh A, Bhaduri G. Endothelial cell loss after small incision cataract surgery. Nepalese journal of ophthalmology. 2011; 3(2): 177-80. doi: 10.3126/nepjoph.v3i2.5273.

17) Bourne RR, Minassian DC, Dart JK, Rosen P, Kaushal S, Wingate N. Effect of cataract surgery on the corneal endothelium: modern phacoemulsification compared with extracapsular cataract surgery. Ophthalmology. 2004; 111(4): 679-85. doi: 10.1016/j.ophtha.2003.07.015.

18) Rosado-Adames N, Afshari NA. The changing fate of the corneal endothelium in cataract surgery. Current opinion in ophthalmology. 2012; 23(1): 3-6. doi: 10.1097/ICU.0b013e32834e4b5f.

19) Rajavi Z, Katibeh M, Ziaei H, Fardesmaeilpour N, Sehat M, Ahmadieh H, et al. Rapid assessment of avoidable blindness in Iran. Ophthalmology. 2011; 118(9): 1812-8. doi: 10.1016/j.ophtha.2011.01.049.

20) Wang D, Amoozgar B, Porco T, Wang Z, Lin SC. Ethnic differences in lens parameters measured by ocular biometry in a cataract surgery population. PloS one. 2017; 12(6): e0179836. doi: 10.1371/journal.pone.0179836.

21) Shahbazi S, Studnicki J, Warner-Hillard CW. A cross-sectional retrospective analysis of the racial and geographic variations in cataract surgery. PloS one. 2015; 10(11): e0142459. doi: 10.1371/journal.pone.0142459.

22) Mohammadpour M, Jafannasab M, Javadi M. Outcomes of acute postoperative inflammation after cataract surgery. European journal of ophthalmology. 2007; 17(1): 20-8. doi: 10.1177/112067210701700104. PMID: 17294379.

23) Hashemi H, Alipour F, Mehravaran S, Rezvan F, Fotouhi A, Alaedini F. Five year cataract surgical rate in Iran. Optometry and vision science: official publication of the American Academy of Optometry. 2009; 86(7): 890-4. doi: 10.1097/OPX.0b013e3181ae1cc6.

24) O'Brien PD, Fitzpatrick P, Kilmartin DJ, Beatty S. Risk factors for endothelial cell loss after phacoemulsification surgery by a junior resident. Journal of cataract and refractive surgery. $2004 ; 30(4)$ : 839-43. doi: 10.1016/s0886-3350(03)00648-5. 
25) Faramarzi A, Javadi MA, Karimian F, Jafarinasab MR, Baradaran-Rafii A, Jafari F, et al. Corneal endothelial cell loss during phacoemulsification: bevel-up versus bevel-down phaco tip. Journal of cataract and refractive surgery. 2011; 37(11): 1971-6. doi: 10.1016/j.jcrs.2011.05.034.

26) Yamazoe K, Yamaguchi T, Hotta K, Satake Y, Konomi K, Den S, et al. Outcomes of cataract surgery in eyes with a low corneal endothelial cell density. Journal of cataract and refractive surgery. $2011 ; 37(12)$ : 2130-6. doi: 10.1016/j.jcrs.2011.05.039.

27) Conrad-Hengerer I, Al Juburi M, Schultz T, Hengerer FH, Dick HB. Corneal endothelial cell loss and corneal thickness in conventional compared with femtosecond laser-assisted cataract surgery: three-month follow-up. Journal of cataract and refractive surgery. 2013; 39(9): 1307-13. doi: 10.1016/j.jcrs.2013.05.033.

28) Mencucci R, Ponchietti C, Virgili G, Giansanti F, Menchini U. Corneal endothelial damage after cataract surgery: Microincision versus standard technique. Journal of cataract and refractive surgery. 2006; 32(8): 1351-4. doi: 10.1016/j.jcrs.2006.02.070.

29) Holzer MP, Tetz MR, Auffarth GU, Welt R, Volcker HE. Effect of Healon5 and 4 other viscoelastic substances on intraocular pressure and endothelium after cataract surgery. Journal of cataract and refractive surgery. 2001; 27(2): 213-8. doi: 10.1016/S0886-3350(00)00568-X.

30) Hayashi K, Hayashi H, Nakao F, Hayashi F. Risk factors for corneal endothelial injury during phacoemulsification. Journal of cataract and refractive surgery. 1996; 22(8): 1079-84. doi: 10.1016/S08863350(96)80121-0.

31) Joussen AM, Barth U, Çubuk H, Koch HR. Effect of irrigating solution and irrigation temperature on the cornea and pupil during phacoemulsification. Journal of Cataract \& Refractive Surgery. 2000; 26(3): 392-7. doi: 10.1016/S0886-3350(99)00470-8.

32) Walkow T, Anders N, Klebe S. Endothelial cell loss after phacoemulsification: relation to preoperative and intraoperative parameters. Journal of cataract and refractive surgery. 2000; 26(5): 727-32. doi: 10.1016/S0886-3350(99)00462-9.

33) Lundberg $\mathrm{B}$, Jonsson $\mathrm{M}$, Behndig A. Postoperative corneal swelling correlates strongly to corneal endothelial cell loss after phacoemulsification cataract surgery. American journal of ophthalmology. 2005; 139(6): 1035-41. doi: 10.1016/j.ajo.2004.12.080.

34) Behndig A, Lundberg B. Transient corneal edema after phacoemulsification: comparison of 3 viscoelastic regimens. Journal of cataract and refractive surgery. 2002; 28(9): 1551-6. doi: 10.1016/S08863350(01)01219-6.

35) Glasser DB, Schultz RO, Hyndiuk RA. The role of viscoelastics, cannulas, and irrigating solution additives in post-cataract surgery corneal edema: a brief review. Lens and eye toxicity research. 1992; 9(3-4): 351-9. PMID: 1301791.

36) O'Neal MR, Polse KA. Decreased endothelial pump function with aging. Investigative ophthalmology \& visual science. 1986; 27(4): 457-63. PMID: 3957564.

37) Kim J, Jo M, Brauner S, Ferrufino-Ponce Z, Ali R, Cremers S, et al. Increased intraocular pressure on the first postoperative day following resident-performed cataract surgery. Eye. 2011; 25(7): 929-36. doi: 10.1038/eye.2011.93. PMID: 21527959, PMCID: PMC3178167.

38) Hugod M, Storr-Paulsen A, Norregaard JC, Nicolini J, Larsen AB, Thulesen J. Corneal endothelial cell changes associated with cataract surgery in patients with type 2 diabetes mellitus. Cornea. 2011;30(7): 749-53. doi: 10.1097/ICO.0b013e31820142d9.

39) Mathew PT, David S, Thomas N. Endothelial cell loss and central corneal thickness in patients with and without diabetes after manual small incision cataract surgery. Cornea. 2011; 30(4): 424-8. doi: 10.1097/ICO.0b013e3181eadb4b.

40) Morikubo S, Takamura Y, Kubo E, Tsuzuki S, Akagi Y. Corneal Changes After Small-Incision Cataract Surgery in Patients With Diabetes Mellitus. Archives of ophthalmology. 2004; 122(7): 966-9. doi: 10.1001/archopht.122.7.966.

41) Cook C. How to improve the outcome of cataract surgery. Community Eye Health. 2000;13(35):37.DOI.PMCID: PMC1705972. 